\title{
ESTIMATIVA DA EVAPOTRANSPIRAÇÃO REAL DIÁRIA UTILIZANDO-SE IMAGENS DIGITAIS TM - LANDSAT 5
}

\author{
BERGSON G. BEZERRA ${ }^{1}$, BERNARDO B. DA SILVA ${ }^{1}$, NELSON J. FERREIRA ${ }^{2}$ \\ ${ }^{1}$ Universidade Federal de Campina Grande (UFCG). \\ ${ }^{2}$ Centro de Previsão de Tempo e Estudos Climáticos (CPTEC). \\ bergson_bezerra@yahoo.com.br.
}

Recebido Abril 2007 - Aceito Janeiro 2008

\begin{abstract}
RESUMO
A quantificação da evapotranspiração é de grande importância na modelagem hidrológica e meteorológica, sendo indispensável no manejo hídrico sustentável de cultivos irrigados. Neste sentido, o presente trabalho tem por objetivo estimar a evapotranspiração real diária - ETr, em escalas local e regional, através de imagens TM - Landsat 5 e dados complementares coletados em estação meteorológica, através da aplicação do SEBAL - Surface Energy Balance Algorithm for Land. A área estudada fica localizada no Cariri cearense, sendo composta por áreas irrigadas, vegetação nativa e parte da floresta da Chapada do Araripe. Foram utilizadas quatro imagens, obtidas em 29 de setembro, 15 e 31 de outubro e 16 de novembro de 2005. A ETr diária foi estimada a partir da densidade de fluxo de calor latente (LE), obtida como resíduo da equação do balanço de energia. O SEBAL é constituído de várias etapas, que incluem calibração radiométrica, cômputo da reflectância e albedo, índices de vegetação e emissividade, baseados nas bandas reflectivas de sensores orbitais, e neste caso o TM - Landsat 5, além da temperatura da superfície (banda termal). Os resultados obtidos foram validados com medições da ETr obtidas em dois campos irrigados com mamona (Ricinus communis L.) e algodão (Gossypium hirsutum). A ETr diária média da área estudada apresentou valores de 3,8, 3,7, 4,6 e 3,4 mm.dia-1, para os dias 272, 288, 304 e 320, respectivamente. Quando comparados com medidas efetuadas nos campos irrigados de algodão e mamona os valores da ETr estimados pelo SEBAL apresentaram diferenças inferiores a 1,0 mm dia-1, evidenciando a sua importância e acurácia.

Palavras Chave: Radiância espectral, balanço de energia, evapotranspiração real, SEBAL.
\end{abstract}

\begin{abstract}
ASSESSMENT OF DAILY ACTUAL EVAPOTRANSPIRATION USING TM - LANDSAT 5 DIGITAL IMAGES

Quantification of evapotranspiration is of great importance for hydrological and meteorological modeling and indispensable for water management of irrigated crops. In this sense the main objective of this study was the estimation of actual daily evapotranspiration (Etr), in local and regional scale, utilizing the SEBAL (Surface Energy Balance Algorithm for Land). The TM - Landsat 5 images and weather data were used in order to assess the energy balance components. The studied area is located in Cariri region, Ceará State, and is composed by irrigated areas, native vegetation and part of the Chapada do Araripe Reserve. Four TM - Landsat 5 images of September $29^{\text {th }}$, October $15^{\text {th }}$, October $31^{\text {st }}$ and November $16^{\text {th }}$ of 2005 , were used. Daily ETr was estimated based on the density of latent heat flux, obtained as residue of the energy balance equation. The application of the SEBAL algorithm includes some steps as radiometric calibration, estimation of the reflectance and albedo, emissivity and vegetation index, based on the reflective bands of the orbital sensors and further on the surface temperature (thermal band) for the TM - Ladsat 5. Two irrigated fields of castor bean and cotton were used do validated the ETr estimated values. The reference evapotranspiration was obtained by FAO-Penman-Monteith method. The mean daily ETr over the studied area presented values of $3.8,3.7,4.6$ and $3.4 \mathrm{~mm} \cdot \mathrm{dia}^{-1}$ on $29 / 09,15 / 10,31 / 10$ and 16/11, respectively. When compared to measured data in the castor bean (Ricinus communis L.) and cotton (Gossypium hirsutum) irrigated crops, the ETr values obtained with SEBAL present differences smaller than 1,0 $\mathrm{mm} \mathrm{day}^{-1}$, showing its importance and accuracy.
\end{abstract}

Keywords: Spectral radiance, energy balance, actual evapotranspiration, SEBAL 


\section{INTRODUÇÃO}

O conhecimento da evapotranspiração real - ETr das culturas e da vegetação em geral é de fundamental importância em atividades ligadas a gestão de bacias hidrográficas, em modelagens meteorológica e hidrológica e, sobretudo, no manejo hídrico da agricultura irrigada. Neste contexto, os métodos que calculam ETr a partir de imagens de satélites se mostram muito úteis, pois são capazes de propiciar a sua determinação em áreas com grande heterogeneidade e dimensão, ao contrário de métodos micrometeorológicos, como o das correlações turbulentas e da razão de Bowen e mesmo o de medidas diretas com lisímetros. Esses métodos, apesar de precisos, apresentam resultados válidos para áreas com culturas com as mesmas condições fenológicas, hídricas, de configuração de plantio e, quando irrigadas, sujeitas a um mesmo sistema de irrigação.

Dentre os métodos que utilizam imagens de satélites, o SEBAL, proposto por Bastiaanssen (1995), tem sido aplicado com êxito em diversos ecossistemas do globo na obtenção da $\mathrm{E} \operatorname{Tr}$ (Bastiaanssen et al., 1998; Bastiaanssen, 2000; Haafez et al., 2002; Silva et al., 2005; Silva e Bezerra, 2006), bem como, na estimativa do rendimento de culturas (Bastiaanssen e Ali, 2003; Samarasinghe, 2003). A ETr é determinada com o SEBAL a partir da quantificação da densidade de fluxo de calor latente - LE, que é obtido como resíduo da equação do balanço de energia - BE. O mesmo pode ser aplicado a dados radiométricos de qualquer sensor orbital que efetue medidas da radiância no visível, infravermelho próximo e infravermelho termal. Dessa forma, o mesmo tem sido aplicado a imagens do Mapeador Temático - TM do satélite Landsat 5 (Bastiaanssen et al., 1998; Bastiaanssen, 2000; Silva et al., 2005; Silva e Bezerra, 2006), NOAA-AVHRR (Timmermans e Meijerink, 1999; Bastiaanssen e Ali, 2003; Hemakumara et al., 2003; Samarasinghe, 2003), Terra/MODIS (Hafeez et al., 2002) e Terra/ASTER (Wang et al., 2005; Hafeez et al., 2002).

O saldo de radiação ( $R$ n), variável chave no cômputo do $\mathrm{BE}$, é obtido através de onze passos computacionais, conforme ilustrado na Figura 1, que envolve calibração radiométrica, cálculo da reflectância e do albedo no topo da atmosfera. Em seguida, é processada correção atmosférica do albedo, obtenção de índices de vegetação e de emissividades termal e da superfície (Allen et al., 2002a). Allen et al. (2002b), no entanto, propõem o uso do METRIC, que é um aprimoramento do SEBAL, no qual as correções atmosféricas são aplicadas às reflectâncias de cada uma das seis bandas do TM - Landsat 5. Nesse mesmo trabalho ainda foi proposta uma correção quanto aos valores da densidade de fluxo de calor sensível $(\mathrm{H})$, obtidos em áreas muito áridas, pois os mesmos constataram haver superestimativas de H obtida com o SEBAL, em tais áreas. Concluíram que a adição de uma resistência aerodinâmica de $50 \mathrm{~s} \mathrm{~m}^{-1}$ àquela obtida com o SEBAL em pixels de áreas áridas apresentou resultados de $\mathrm{H}$ mais consistentes. Ademais, foi sugerido que a escolha do pixel frio da imagem fosse feita em área com cultivo agrícola com cobertura total do solo, plenamente abastecido de água e que sua temperatura fosse comparativamente inferior aos demais pixels da cena estudada, diferentemente do que era proposto no SEBAL, que recaia sobre um pixel no interior de um grande corpo de água.

A densidade de fluxo de calor no solo - G é altamente dependente da condição, textura e ocupação do solo e no SEBAL o mesmo é determinado em função do NDVI - Normalized Difference Vegetation Index, temperatura da superfície, albedo e Rn.

O cerne do SEBAL, no entanto, é o cômputo da densidade de fluxo de calor sensível - H que é obtida com base na teoria da similaridade de Monin-Obukhov através de um processo iterativo levando em consideração as condições de estabilidade atmosférica. Para tanto, são escolhidos dois pixels âncoras, denominados de "quente" e "frio", que devem ser escolhidos sobre áreas que apresentem valores extremos de ETr. Em Bastiaanssen (1995) e aplicações subseqüentes (Bastiaanssen, 2000; Allen et al., 2002a; Bezerra, 2004; Feitosa, 2005; Silva e Bezerra, 2005; Bezerra, 2006) o valor de H é considerado nulo no pixel frio, o que maximiza o LE nesse pixel, dado por $\mathrm{LEF}=\mathrm{RnF}-\mathrm{GF}$, onde o subscrito $\mathrm{F}$ refere-se ao pixel frio. $\mathrm{O}$ pixel quente é escolhido de modo que se possa admitir $\mathrm{LE}=0$ e a sua identificação requer um cuidado especial, de modo a evitar que o mesmo recaia sobre rochas, por exemplo. Conseqüentemente, $\mathrm{H}=\mathrm{Rn}-\mathrm{G}$, nesse pixel quente.

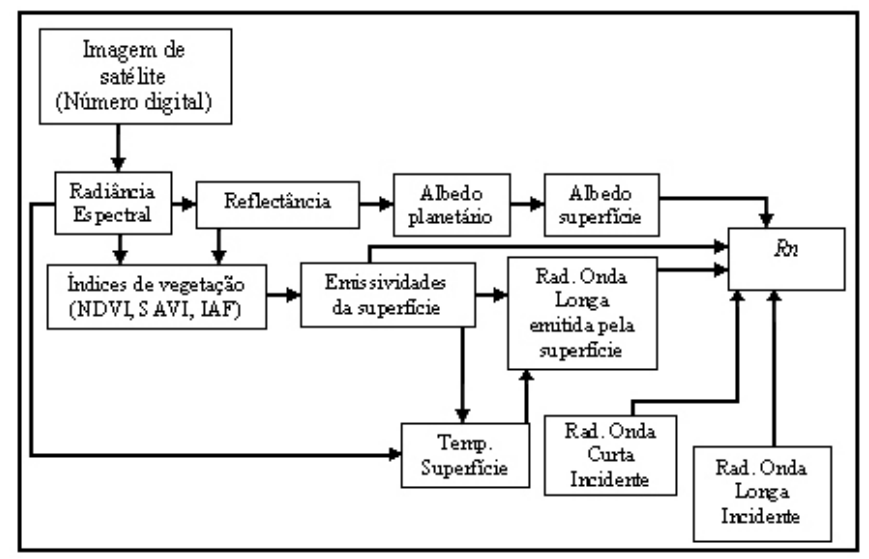

Figura1: Esquema representativo das etapas computacionais para obtenção do saldo de radiação (Rn), utilizando-se o SEBAL

Com o propósito de desenvolver um modelo operacional e adaptado às condições específicas do sul do estado americano de Idaho, Trezza (2002) propôs algumas modificações significantes ao SEBAL original (Bastiaanssen, 1995; Bastiaanssen et al., 1998). Uma dessas modificações é a mudança na definição do balanço de energia dos pixels âncoras. 
Para o pixel frio, que foi escolhido sobre uma área bem irrigada, completamente coberta pela cultura e com características de um campo agrícola coberto por alfafa saudável e vigorosa transpirando a um taxa potencial, foram assumidas as seguintes relações: $\mathrm{ET}=1,05 . \mathrm{ET}_{0}, \mathrm{H}=\mathrm{Rn}$-G-LET e a diferença de temperatura entre a superfície e uma altura de referência foi calculada por $d T=T_{2}-T_{1}=H \cdot r_{a h} /\left(p . c_{P}\right)$, onde $\mathrm{ET}_{0}$ é a evapotranspiração de referência, calculado pela equação Penman-Monteith, desenvolvida pela ASCE-EWRI (2002) para alfafa. Ainda de acordo com Trezza (2002) a suposição de que a $E T_{\text {(pixelfrio) }}=1,05^{*} E T_{0}$ presume que a evapotranspiração dos pixels próximos ao mais frio pode ser $5 \%$ superior a evapotranspiração de referência e o incremento de $5 \%$ pode contemplar diferentes cenários, tais como: a) condição de alfafa recém irrigada; b) culturas diferentes de alfafa com baixa resistência aerodinâmica a evapotranspiração; e c) que as características da cultura no pixel frio podem ser muito diferentes das características da cultura de referência usada na $\mathrm{ET}_{0}$ alfa.

Já para o pixel quente, que foi escolhido sobre áreas agrícolas em desuso (solo exposto), Trezza (2002), propôs as seguintes relações para o balanço de energia: $H=R n-G-L E T$ e $d T=T_{2}-T_{1}=H . r_{a h} /\left(p . c_{P}\right)$. A estimativa da ET do pixel quente foi feita mediante um balanço hídrico usando metodologia proposta na FAO-56 (Allen et al.1998). Segundo Trezza (2002), a aplicação do balanço hídrico se faz necessária quando há registro de incidência de chuvas nos 5 ou 6 dias que antecedem o imageamento. Neste caso é provável que existam resíduos de umidade do solo.

A principal contribuição de Trezza (2002), no entanto, foi a proposta para o procedimento da extrapolação da ETr instantânea para valores diários. Na proposta original do SEBAL (Bastiaanssen, 1995) e em aplicações subseqüentes (Bastiaanssen et al., 1998; Bastiaanssen, 2000; Feitosa, 2005) esta extrapolação era feita ao se assumir que a fração evaporativa - FE instantânea era igual à $\mathrm{FE}$ diária. Ocorre que em várias ocasiões essa hipótese resultava em superestimativa da $\mathrm{ET}_{\mathrm{r}}$ diária, quando ocorresse, por exemplo, presença de nuvens antes ou depois da obtenção da imagem. Com a proposta de Trezza (2002), a FE foi substituída pela fração de evapotranspiração de referência $\left(\mathrm{FET}_{0}\right)$, que relaciona a evapotranspiração real instantânea, integrada ao longo de uma hora, e a evapotranspiração de referência horária. Portanto, a $\mathrm{ET}_{\mathrm{r}}$ diária seria função da $\mathrm{FET}_{0}$ e da $\mathrm{ET}_{0}$ diária, que contempla as variações dos elementos do tempo antes, durante e após o imageamento da área.

Em vários países em que foi aplicado, o SEBAL tem sido validado, alcançando resultados bastante precisos. Nos campos experimentais de EFEDA (Espanha), HAPEX-Sahel (Nigéria), HEIFE - Bacia do Rio Heihe (China) e no Delta do Nilo (Egito) (Bastiaanssen et al., 1998), as comparações entre as estimativas da ETr obtidas com o SEBAL e valores medidos apresentaram diferenças dentro da faixa de incertezas instrumentais em $85 \%$ dos casos. No Nordeste brasileiro, o SEBAL foi validado com dados medidos em Caatinga, apresentando diferenças da ordem de 10\% (Feitosa, 2005).

Diante do exposto esta pesquisa tem por objetivo estimar a ETr para a região do Cariri cearense com base na $\mathrm{FET}_{0}$ e fazer a validação do SEBAL com dados medidos pela técnica de razão de Bowen em campos irrigados de algodão e mamona.

\section{MATERIAIS E MÉTODOS}

\section{1 Área de Estudo}

A área estudada fica localizada na mesorregião do Cariri, no sul do estado do Ceará (CE), no Nordeste brasileiro. A cena estudada, a qual está reapresentada na Figura 2, é composta de uma parcela da Floresta Nacional do Araripe, localizada sobre a Chapada do Araripe, que corresponde a grande área homogênea no canto inferior esquerdo, vegetação nativa de densidade variada, que correspondem as áreas com diferentes tons de cinza, e dois corpos d'água, áreas pretas localizadas na parte superior. Ainda constituem a cena cultivos agrícolas irrigados e de sequeiro, o campo experimental da Embrapa/Algodão e os núcleos urbanos das cidades cearenses de Barbalha, Crato e Juazeiro do Norte, todos localizados e identificados na cena da Figura 2, que é uma composição falsa cor dos canais 5 , 4 e 3 do TM - Landsat 5 .

A escolha da área foi motivada por a região compreender um importante pólo econômico do Nordeste brasileiro, sobretudo na atividade de agricultura irrigada e a importância da Chapada da Araripe para o meio ambiente e clima regional. O clima da região, de acordo com a classificação climática de Thornthwaith e Mather (1955), citada por Borges (2002) e Rodrigues (2003), é do tipo $\mathrm{C}_{1} \mathrm{~S}_{2} \mathrm{~A}^{\prime} \mathrm{a}$ ', o que implica em um clima sub-úmido, com pequeno excesso hídrico durante a estação chuvosa, megatérmico e com vegetação durante o ano.

\subsection{Imagens de Satélite}

Foram utilizadas quatro imagens TM - Landsat 5 da órbita 217 e ponto 65 , adquiridas sob a condição de céu claro, nos dias 29 de setembro (DA 272), 15 (DA 288) e 31 de outubro (DA 304), além de 16 de novembro (DA 320) do ano de 2005. $\mathrm{O}$ termo DA significa dia do ano.

\section{3 - Método Utilizado}

O cálculo da evapotranspiração diária - ETr foi efetuado através da equação:

$$
E T r=F E T 0 \_24 E T_{0 \_24}\left(\mathrm{~mm} \cdot \mathrm{dia}^{-1}\right)
$$




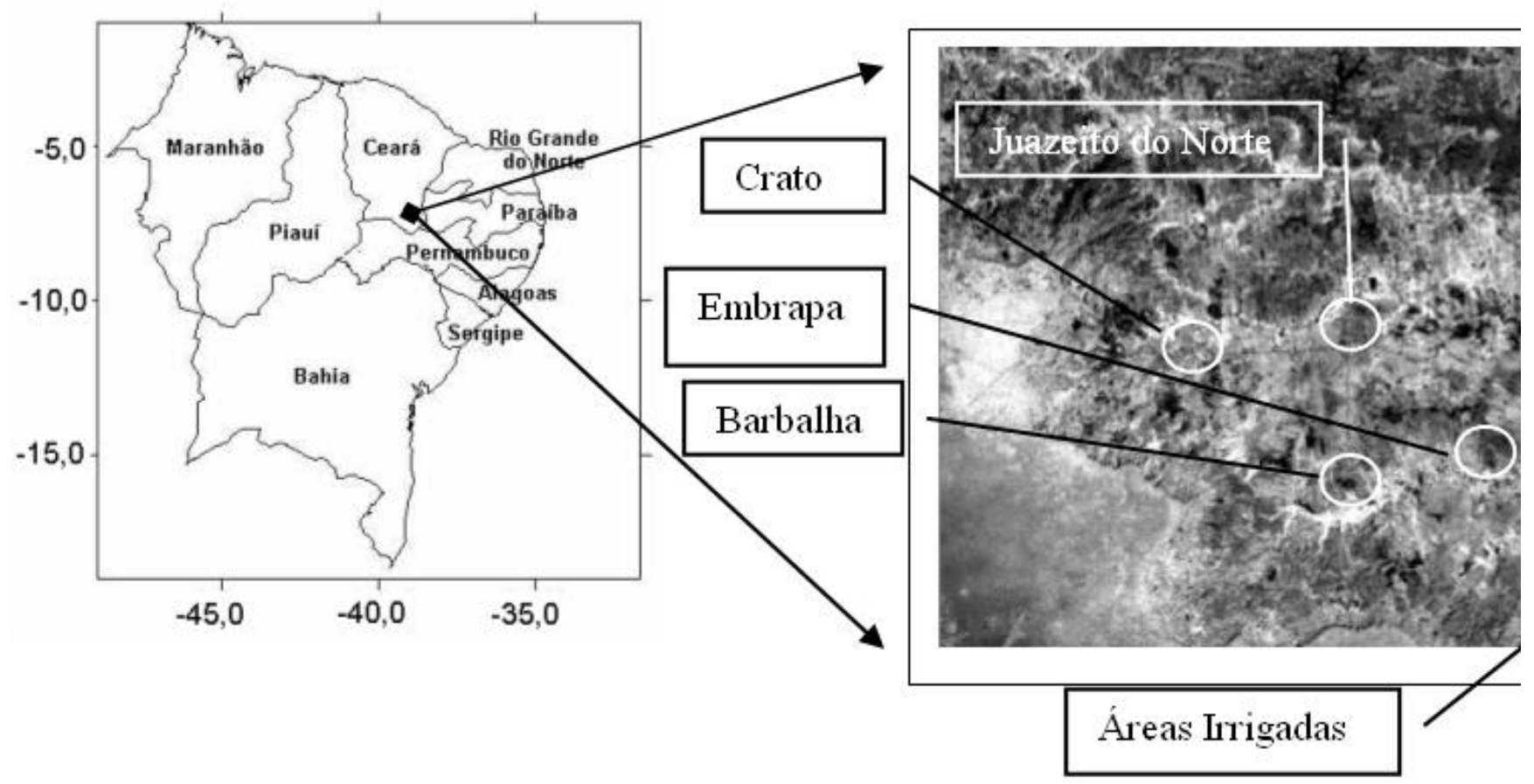

Figura 2 - Mapa da região Nordeste com a indicação da localização da área e a cena estudadaque é a refletância do canal 4 do TM - Landsat 5

onde FET0_24 é a fração da evapotranspiração de referência diária, que segundo Trezza (2002), pode ser considerada igual à fração de evapotranspiração de referência horária, FET0_h, obtida por:

$$
F E T_{0 \_}=E T_{r_{-} h} / E T_{0 \_}
$$

em que $\mathrm{ET}_{\mathrm{r}_{-} \mathrm{h}}$ é a evapotranspiração real horária e a $\mathrm{ET}_{0_{-} \mathrm{h}} \mathrm{e}$ evapotranspiração de referência horária. Tanto a $\mathrm{ET}_{0}{ }_{24}$ como a $\mathrm{ET}_{0 \mathrm{~h}}$ foram calculadas pelo método da FAO-Penman-Monteith (Allen et al., 1998), com dados que incluam radiação global, temperatura do ar, velocidade do vento e umidade relativa do ar, coletados na estação meteorológica localizada em Barbalha - CE.

$\mathrm{AET}_{\mathrm{r}_{-} \mathrm{h}}\left(\mathrm{mm} \mathrm{h}^{-1}\right)$ foi obtida, em cada pixel da imagem, segundo expressão:

$$
E T_{r_{-} h}=3600 \mathrm{LE} / \mathrm{L}
$$

onde LE $\left(\mathrm{W} \mathrm{m}^{-2}\right)$ é a densidade de fluxo de calor latente, estimado no momento da passagem do satélite, como resíduo da equação do balanço de energia $(L E=R n-G-H)$ e $L(J$ $\mathrm{kg}^{-1}$ ) é o calor latente de vaporização da água.

A densidade de fluxo de calor no solo $\left(\mathrm{W} \mathrm{m}^{-2}\right)$ foi calculada segundo a relação (Bastiaanssen, 2000):

$$
G=\left[T s(0,0038+0,0074 a)\left(1-0,98 N D V I^{4}\right)\right] R n
$$

onde Ts é a temperatura da superfície (oC), $\alpha$ é o albedo da superfície e NDVI - Normalized Difference Vegetation Index. $\mathrm{O}$ saldo de radiação $\left(\mathrm{W} \mathrm{m}^{-2}\right)$ foi obtido segundo critérios do SEBAL e estão bem explicitados em Silva et al. (2005).

A densidade de fluxo de calor sensível $\mathrm{H}\left(\mathrm{W} \mathrm{m}^{-2}\right)$ foi obtida através de processo iterativo, conforme ilustrado na Figura 3. Inicialmente, utiliza-se a velocidade do vento $-\mathrm{u}$ $\left(\mathrm{m} \mathrm{s}^{-1}\right)$ e a altura média da vegetação $-\mathrm{h}(\mathrm{m})$ que envolve a estação meteorológica, no caso específico do presente estudo foi utilizada a altura média da grama, $0,1 \mathrm{~m}$, o que possibilita estimar o coeficiente de rugosidade ao transporte de momentum - $Z_{\mathrm{om}}(\mathrm{m})$. Então, é possível obter a velocidade de friç̧ão - $\mathrm{u}^{*}$ $\left(\mathrm{m} \mathrm{s}^{-1}\right)$ segundo expressão (Allen et al., 2002; Trezza, 2002; Silva e Bezerra, 2006):

$$
U_{*}=k \cdot u / \ln \left(z / Z_{\text {om }}\right)
$$

onde k é a constante de Von Karman, u a velocidade do vento $\left(\mathrm{m} \mathrm{s}^{-1}\right)$ e $\mathrm{z}$ a altura $(\mathrm{m})$ em que ocorreu a medição da velocidade do vento.

Considerando-se a atmosfera em equilíbrio neutro e o perfil logaritmo do vento, projeta-se a velocidade do vento 
a $100 \mathrm{~m}$ (blending heigh), altura esta em que a rugosidade da superfície já não mais interfere na velocidade do vento, admitindo-se, portanto, que naquele nível essa velocidade é espacialmente constante. Logo, a velocidade de fricção de cada pixel é obtida segundo (Allen et al., 2002a; Trezza, 2002; Silva e Bezerra, 2006):

$$
u_{*}=k \cdot u_{100} / \ln \left(100 / z_{\text {om }}\right)
$$

em que $\mathrm{u} 100\left(\mathrm{~m} \mathrm{~s}^{-1}\right)$ é a velocidade do vento a $100 \mathrm{~m} \mathrm{e}_{\text {om }}(\mathrm{m})$ é obtido pixel a pixel em função da imagem do SAVI - Soil Adjusted Vegetation Index, segundo equação desenvolvida por Bastiaanssen (2000). De posse dos valores de $u_{*}$, estimou-se a resistência aerodinâmica ao transporte de momentum $-r_{\text {ah }}$, segundo expressão (Allen et al., 2002; Trezza, 2002; Silva e Bezerra, 2006):

$$
r_{a h}=\frac{\ln \left(z_{2} / z_{1}\right)}{u_{*} k}
$$

onde $z_{1}$ e $z_{2}$ são as alturas acima da superfície, normalmente tomados $0,1 \mathrm{~m}$ e $2,0 \mathrm{~m}$, respectivamente.

$\mathrm{O}$ cômputo da diferença da temperatura do ar em dois níveis próximos à superfície é feito admitindo-se que essa diferença pode ser obtida em função da temperatura radiométrica de cada pixel, ou seja:

$$
d T=a+b T s
$$

onde a e b são coeficientes obtidos com base das condições verificadas nos pixels âncoras e Ts é a temperatura de cada pixel (oC).

O pixel frio foi escolhido sobre a reserva florestal da Chapada do Araripe, que apesar de se localizar no sertão nordestino, apresenta vegetação típica de floresta úmida mescladas com espécies do cerrado. O NDVI do pixel frio foi da ordem de 0,75 e assumiu-se que $\mathrm{H}=0$ e, conseqüentemente, $\mathrm{dT}=0$ e a densidade de fluxo de calor latente foi calculada por $\mathrm{LE}=\mathrm{Rn}-\mathrm{G}$. Já o pixel quente foi identificado em área com baixa cobertura vegetal (NDVI $<0,2)$ e onde assumiu-se ser LE $=0$. Portanto, o valor de $\mathrm{H}$ nesse pixel é dado por:

$$
R n-G=\frac{\rho_{a r} c_{p}(a+b T s)}{r_{a h}}
$$

onde $\rho_{\mathrm{ar}}\left(\mathrm{kg} \mathrm{m}^{-3}\right)$ é a massa específica do ar, $\mathrm{c}_{\mathrm{p}}$ o calor específico a pressão constante $\left(\mathrm{J} \mathrm{kg}^{-1} \mathrm{k}^{-1}\right)$ e Ts $(\mathrm{oC}), \mathrm{Rn}\left(\mathrm{W} \mathrm{m}^{-2}\right)$ e $\mathrm{G}(\mathrm{W}$ $\mathrm{m}^{-2}$ ) são obtidos o pixel quente de cada imagem. Com base nesses valores, obtém-se:

$$
a+b T s=\frac{r_{a h}(R n-G)}{\rho_{a r} c_{p}}
$$

Como no pixel frio $\mathrm{dT}=0$, ou seja, $\mathrm{dT}=\mathrm{a}+\mathrm{b} \mathrm{Ts}=0$, tem-se um sistema de duas equações e duas incógnitas, no caso a e b, possibilitando, portanto, a determinação de dT em todos os pixels da imagem, segundo:

$$
H=\frac{\rho_{a r} c_{p}(a+b T s)}{r_{a h}}
$$

em que Ts e $\mathrm{r}_{\mathrm{ah}}$ representam a temperatura $\left({ }^{\circ} \mathrm{C}\right)$ e a resistência aerodinâmica ao transporte de calor sensível $\left(\mathrm{s} \mathrm{m}^{-1}\right)$, respectivamente, de cada pixel das imagens.

Os valores de $\mathrm{H}$ obtidos até então, no entanto, não representam adequadamente o fluxo de calor sensível de cada pixel e servem, conforme mencionado, como valores iniciais de um processo iterativo em que, nas etapas seguintes, se considerada, efetivamente, a condição de estabilidade de cada pixel. Nesse sentido, o comprimento de Monin-Obukhov L (m) foi utilizado na identificação da condição de estabilidade atmosférica de cada pixel e, na seqüência, foram obtidas as funções adimensionais para correção da estabilidade para o transporte de momentum $\left(\psi_{\mathrm{m}}\right)$ e calor sensível $\left(\psi_{\mathrm{h}}\right)$, que uma vez determinados (Bastiaanssen, 1995; Morse et al., 2000; Allen et al., 2002a; Silva e Bezerra, 2006) possibilitaram corrigir a velocidade de fricção $u_{*}\left(\mathrm{~m}^{-1}\right)$, segundo:

$$
u_{*}=\frac{k u_{100}}{\ln \left(\frac{100}{z_{0 m}}\right)-\psi_{m(100 m)}}
$$

onde $\mathrm{u}_{100} \mathrm{e} \mathrm{k}$ são constantes, $\mathrm{z}_{0 \mathrm{~m}} \mathrm{já}$ fora definido anteriormente, $\Psi_{\mathrm{m}(100 \mathrm{~m})}$ é o fator de correção de estabilidade atmosférica para o transporte de momentum, obtido pixel a pixel, em função da imagem do comprimento de Monin-Obukhov L (m) de acordo com Allen et al. (2002).

De posse do $\mathrm{u}_{*}$ corrigido, foi obtida a resistência aerodinâmica ao transporte de calor corrigido $-\mathrm{r}_{\mathrm{ah}}$, de acordo com equação (Bastiaanssen, 1995, Morse et al., 2000; Allen et al., 2002a):

$$
r_{a h}=\frac{\ln \left(\frac{z_{2}}{z_{1}}\right)-\psi_{h\left(z_{2}\right)}+\psi_{h\left(z_{1}\right)}}{u_{*} k}
$$


onde $\psi_{h\left(z_{2}\right)}$ e $\psi_{h\left(z_{1}\right)}$ são as funções adimensionais para correções da estabilidade para o transporte de calor a 2,0 m e $0,1 \mathrm{~m}$, respectivamente, calculadas em função do comprimento de Monin-Obukhov pixel a pixel de acordo com Allen et al. (2002).

Depois de obtidos os valores desses parâmetros, retornase ao cômputo do dT e, na seqüência, de $\mathrm{H}$ com os novos valores de $r_{a h}$. Esse processo deve ser repetido até que seja verificada estabilidade dos valores sucessivos da diferença de temperatura $(\mathrm{dT})$ e da resistência aerodinâmica $\left(\mathrm{r}_{\mathrm{ah}}\right)$ no pixel quente. Para tanto, foram necessárias de seis a sete iterações com as imagens.

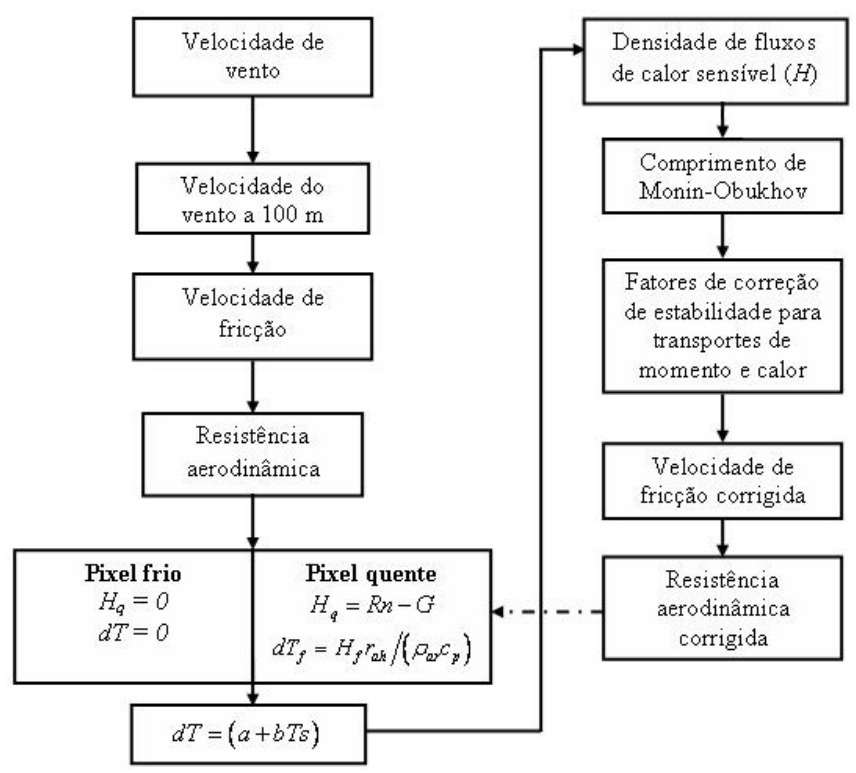

Figura 3 - Esquema representativo do processo iterativo para obtenção do fluxo de calor sensível $(\mathrm{H})$.

\subsection{Análise Comparativa}

A comparação entre a ETr medida (razão de Bowen) e estimada (SEBAL) foram feitas mediante o cálculo dos erros absoluto e relativo, de acordo com as expressões 14 e 15, respectivamente:

ErroAbsoluto $=\mid E \operatorname{Tr}($ RazãoBowen $)-E \operatorname{TrSEBAL}$

ErroRelativo $=\mid($ ETr(RazãoBowen $)-$ ETrSEBAL $) \mid$ $\mathrm{ETr}$ (RazãoBowen) | - 100\%

\section{RESULTADOS E DISCUSSÃO}

\subsection{Componentes do balanço de energia}

Nas Figuras 4, 5 e 6 estão representadas as médias de 16 pixels por coluna, dos componentes do $\mathrm{BE}$ obtidos em recortes de área irrigada, em área de vegetação nativa e em área da reserva florestal da Chapada do Araripe, respectivamente, nos dias estudados. Observa-se que o Rn da área irrigada apresentou resultados em torno de $700 \mathrm{~W} \mathrm{~m}^{-2}$ em todos os dias estudados, corroborando com medidas feitas por Borges (2002) e Rodrigues (2003) na cultura do algodão herbáceo, no horário corresponde a passagem do Landsat 5, no Campo Experimental da Embrapa - Algodão, em Barbalha - CE. Valores semelhantes também foram encontrados por Moran et al. (1989) para algodão e alfafa em estudo com dados TM - Landsat 5, muito embora em região bastante diferente da aqui estudada. A área de vegetação nativa (Figura 5) apresentou Rn em torno de $600 \mathrm{~W} \mathrm{~m}^{-2}$, enquanto que a vegetação da reserva florestal da Chapada do Araripe (Figura 6) apresentou valores ligeiramente superiores a $700 \mathrm{~W} \mathrm{~m}^{-2}$.

Os valores de $\mathrm{G}$ e $\mathrm{H}$ na área irrigada apresentaram praticamente os mesmos resultados, com valores em torno de $60 \mathrm{~W} \mathrm{~m}^{-2}$, representando aproximadamente $8,5 \%$ do $\mathrm{Rn}$. Valores dessa magnitude foram obtidos por Ávila Neto (1997), Bastiaanssen (2000), Rodrigues (2003) e Bezerra (2004), também para a cultura do algodão irrigado. A área de vegetação nativa apresentou valores $\mathrm{H}$ em torno de $150 \mathrm{~W} \mathrm{~m}^{-2}$ e $\mathrm{G}$ em torno de $100 \mathrm{~W} \mathrm{~m}^{-2}$. A vegetação da Chapada do Araripe, por sua vez, apresentou valores de $\mathrm{G}$ inferiores a $80 \mathrm{~W} \mathrm{~m}^{-2}$ e valores de $\mathrm{H}$ da ordem de $20 \mathrm{~W} \mathrm{~m}^{-2}$.

A área irrigada apresentou valores da densidade de fluxo de calor latente (LE) da ordem de $600 \mathrm{~W} \mathrm{~m}^{-2}$, o que representa aproximadamente $85 \%$ de $\mathrm{Rn}$, bastante similar aos resultados encontrados por Bastiaanssen (2000) para a cultura do algodão em áreas semi-áridas da Turquia. Rodrigues (2003) obteve 89\% também para cultura do algodão, em Barbalha - CE e Bezerra (2004) encontrou valores de 76\% para áreas irrigadas com sistema de pivô central no Sub-médio São Francisco, Brasil.

\subsection{Evapotranspiração}

Na Figura 7 estão representadas as imagens da ETr para os dias estudados. As áreas com tonalidade vermelha representam áreas da superfície que apresentaram valores de ETr menores que 1,0 $\mathrm{mm} \mathrm{dia}^{-1}$, que correspondem a áreas de solo exposto e/ou de vegetação nativa muita rala e sem folhas, visto que a época do ano aqui estudada corresponde ao período de estiagens. Esses resultados corroboram com os obtidos por Wang et al. (2005) aplicando o SEBAL a imagens ASTER em áreas desérticas e/ou de vegetação esparsa no estado americano do Novo México. Já as áreas em verde-escuro representam a ETr superior a 6,0 $\mathrm{mm} \mathrm{dia}^{-1}$. Observa-se que esses valores concentram-se predominantemente na reserva florestal da Chapada do Araripe, nos espelhos de água (açudes) presentes 


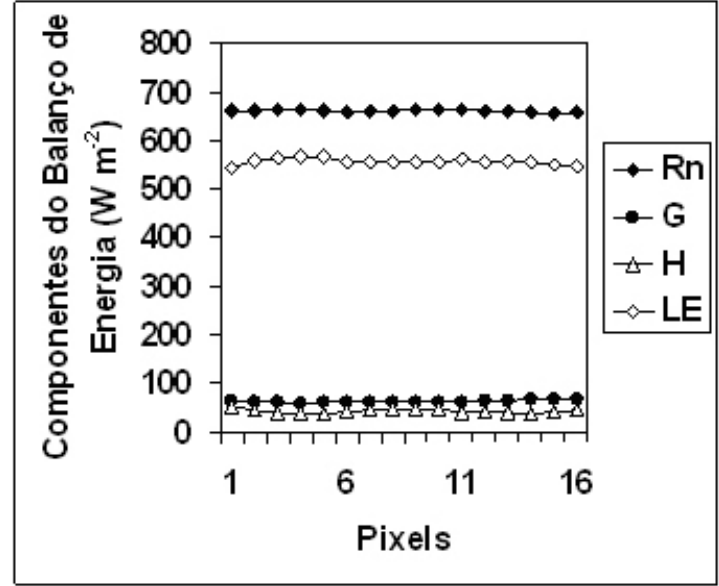

a)

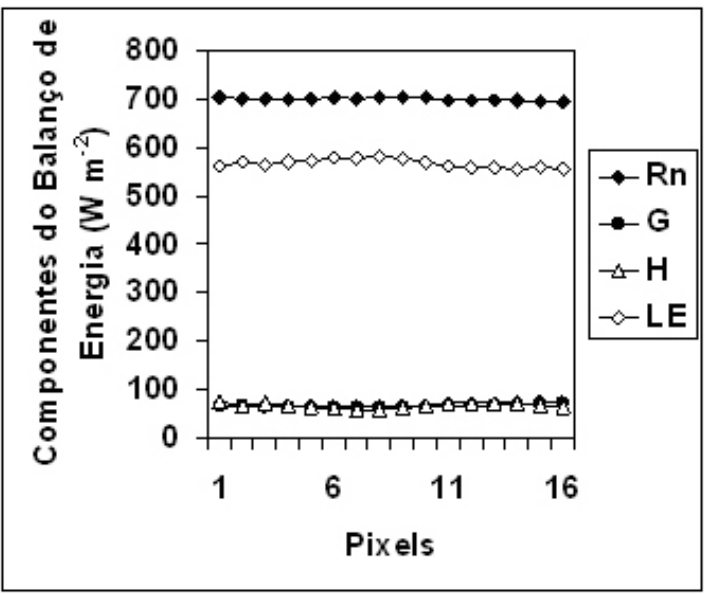

c)

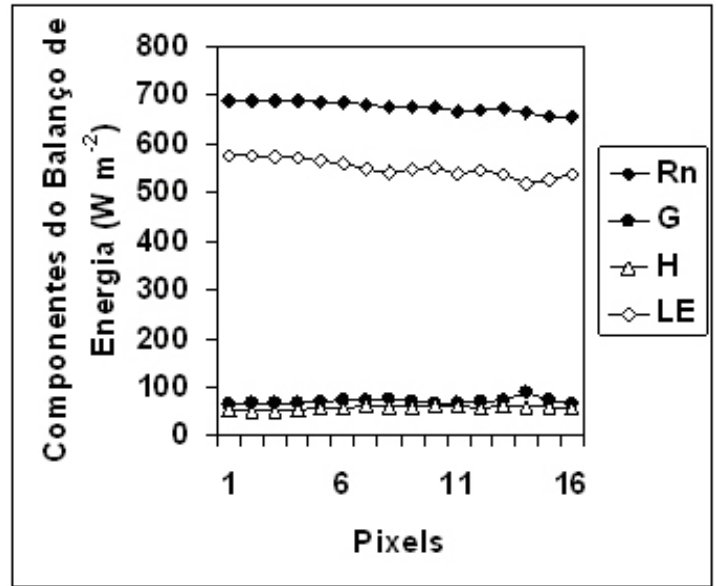

b)

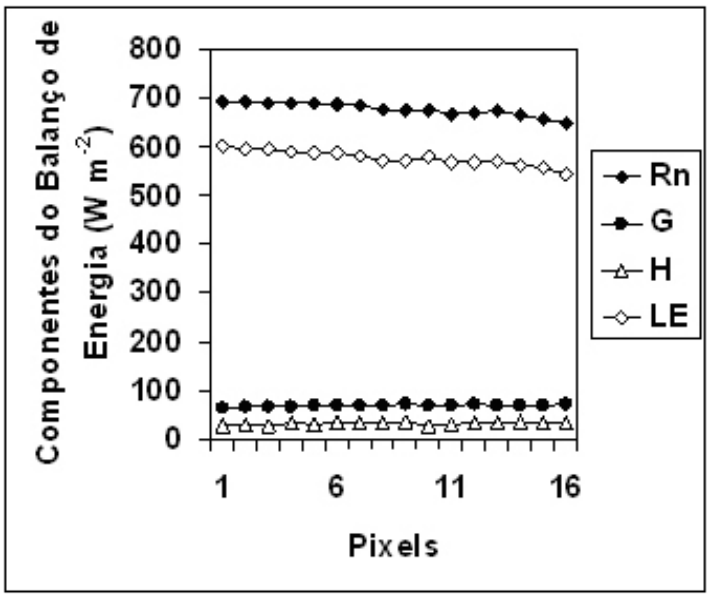

d)

Figura 4 - Variação da média aritmética de 16 pixels por coluna, dos componentes do BE, obtidos em áreas irrigadas nos dias: a) 29/09/2005; b) $15 / 10 / 2005$; c) $31 / 10 / 2005$; e d) e 16/11/2005.

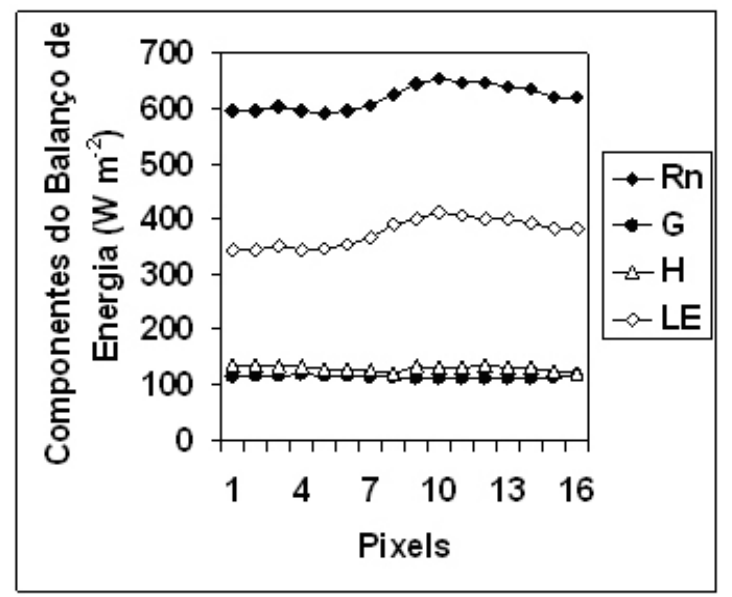

a)

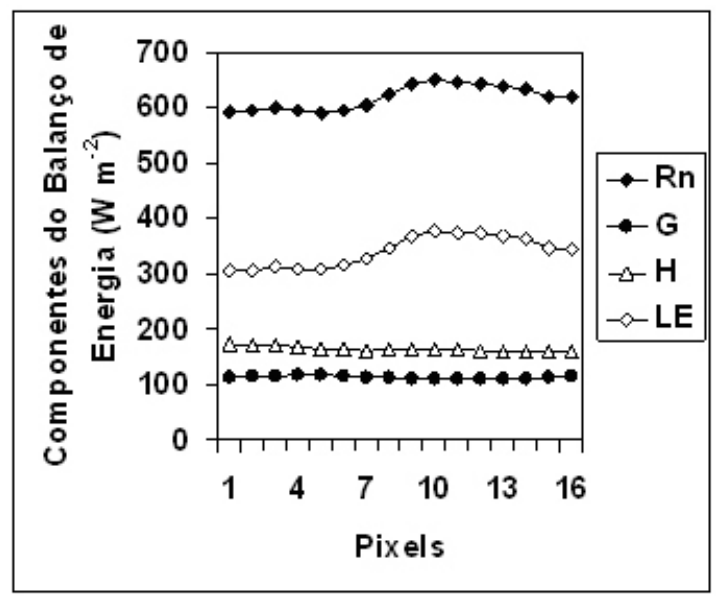

b)

Figura 5 - Variação da média aritmética de 16 pixels por coluna, dos componentes do BE, obtidos na vegetação nativa nos dias: a) 29/09/2005; b) $15 / 10 / 2005$; c) $31 / 10 / 2005$; e d) e 16/11/2005. 


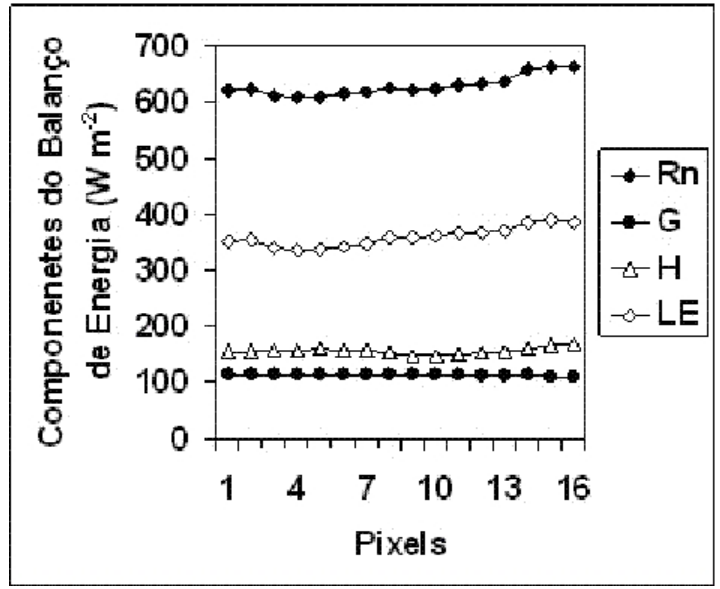

c)

Figura 5 (Continuação)

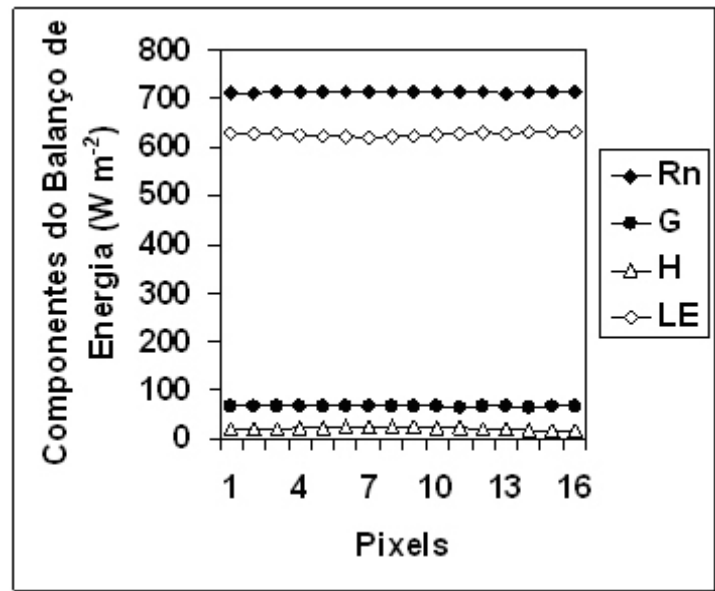

a)

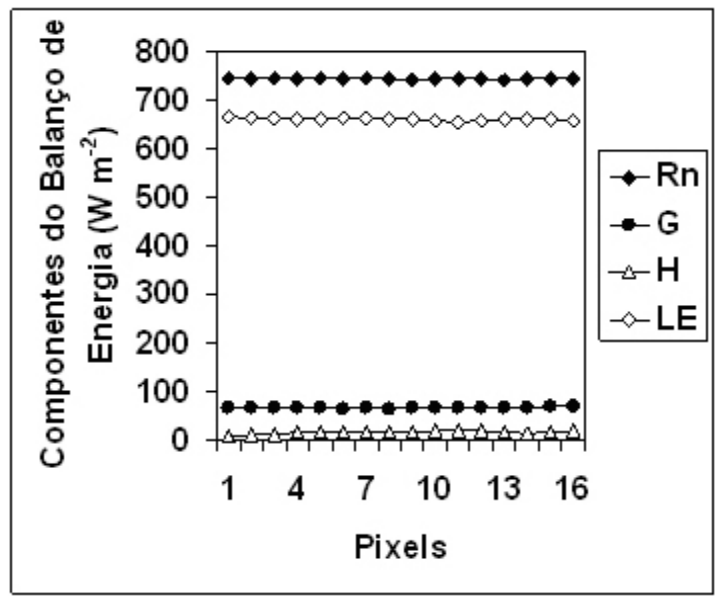

c)

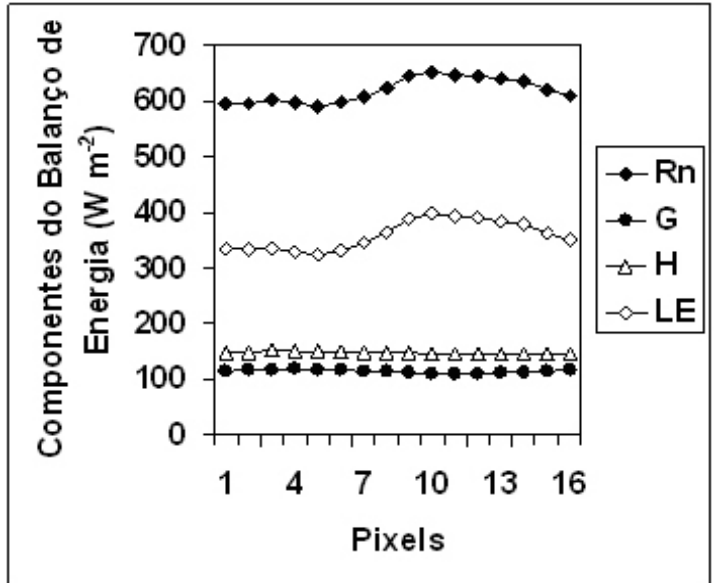

d)

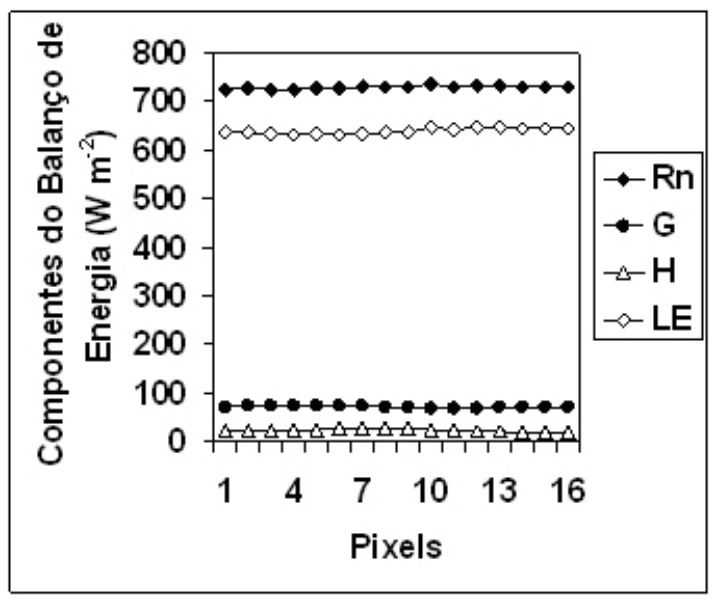

b)

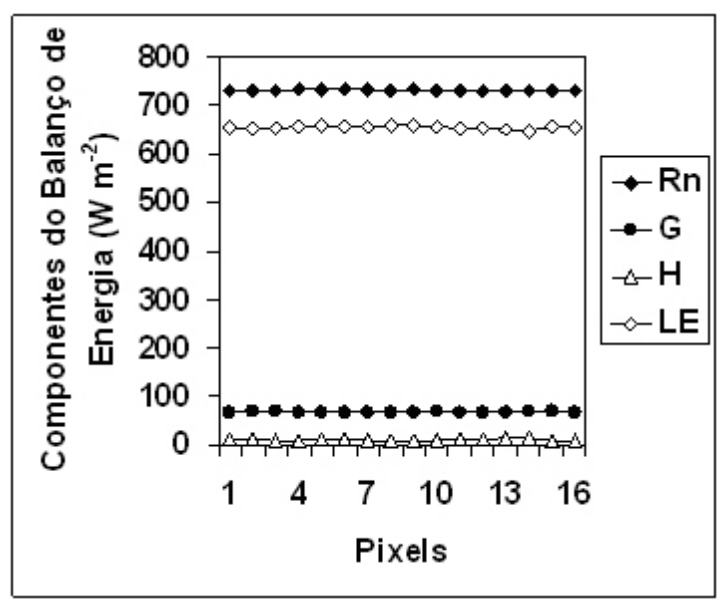

d)

Figura 6 - Variação da média aritmética de 16 pixels por coluna, dos componentes do BE, obtidos na Floresta Nacional da Chapada do Araripe nos dias: a) 29/09/2005; b) 15/10/2005; c) 31/10/2005; e d) e 16/11/2005. 
na parte superior da cena e nos cultivos irrigados localizados no canto inferior direito da cena. Nagler et al. (2005), em estudo no Novo México com dados MODIS, obtiveram valores de 6,0 mm.dia ${ }^{-1}$ para culturas irrigadas (algodão). Na reserva florestal da Chapada do Araripe, a ETr apresentou praticamente o mesmo comportamento nos dias 29/09, 15/10 e 31/10, ou seja, valores bastante uniforme e superiores a $6 \mathrm{~mm} \mathrm{dia}^{-1}$. Já no dia 16/11 observa-se uma mescla de valores ETr acima de $6,0 \mathrm{~mm} \mathrm{dia}^{-1}$ com ETr entre 5,0 e 6,0 $\mathrm{mm} \mathrm{dia}^{-1}$ (cor verde-limão). O restante da cena apresenta grande variabilidade da ETr, com áreas em amarelo (valores entre 1,0 e 2,0 $\mathrm{mm} \mathrm{dia}^{-1}$ ), em azul (entre 2,0 e
3,0 $\mathrm{mm} \mathrm{dia}^{-1}$ ), azul turquesa (entre 3,0 e 4,0 $\mathrm{mm} \mathrm{dia}^{-1}$ ) e magenta (ETr entre 4,0 e 5,0 $\mathrm{mm} \mathrm{dia}^{-1}$ ). Essa variabilidade deve-se a acentuada heterogeneidade da cobertura vegetativa da região, visto que os resultados apresentam bastante similaridade com os obtidos em outros estudos sobre áreas bastantes heterogêneas composta de vegetação perene (árvbórea) e não-perene (arbustiva e pastagens) no Sri Lanka e em Bostuana aplicando o SEBAL a imagens NOAA e TM - Landsat 5 (Hemakumara et al., 2003; Timmermans e Meijerink, 1999). Vale a pena salientar que ambos os estudos foram realizados sobre regiões climáticas bastante diferentes das escolhidas para esta pesquisa.

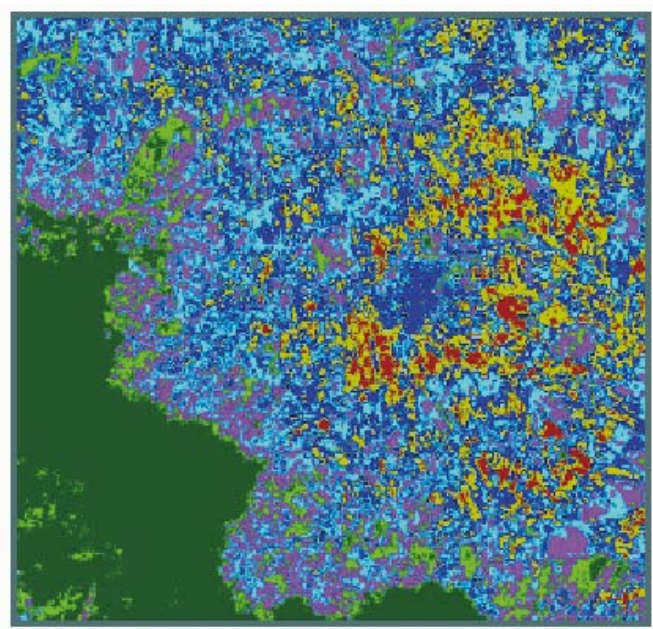

a)

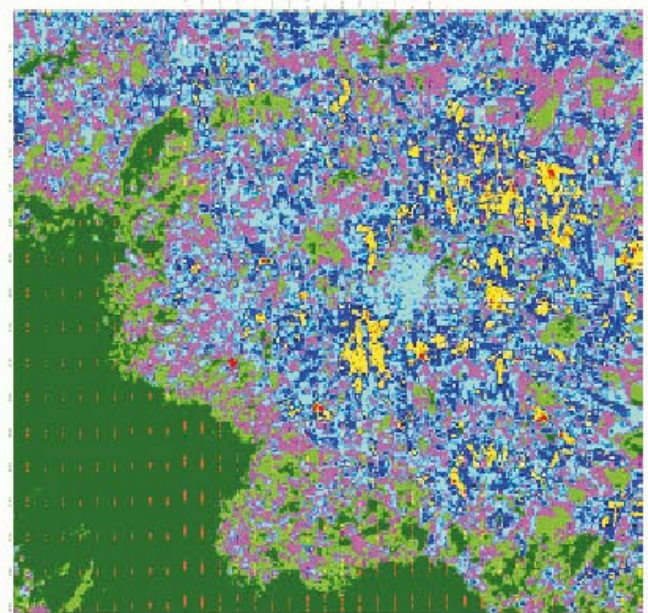

c)

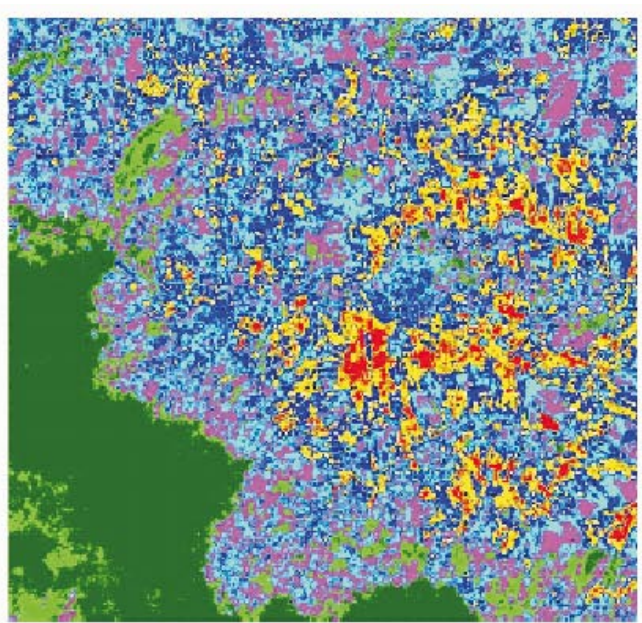

b)

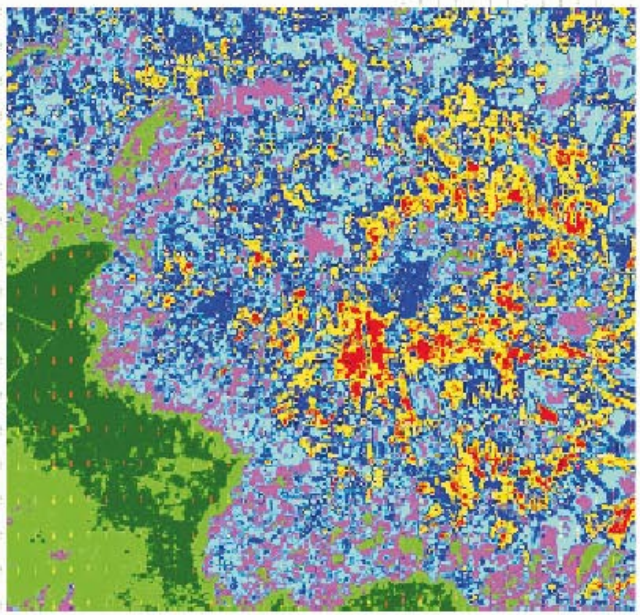

d)

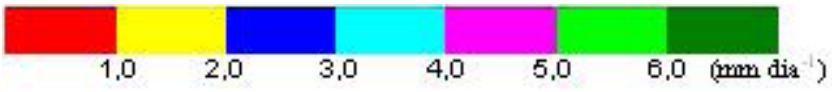

Figura 7 - Imagens da ETr diária nos dias: a) 29/09/2005; b) 15/10/2005; c) 31/10/2005; e d) 16/11/2005. 


\subsection{Validação do SEBAL}

Nas Figuras 8a a 8e apresentam-se os ciclos diurnos da ETr obtida pela técnica de razão de Bowen na cultura do algodão e na mamona. Ainda nos mesmos gráficos estão apresentados os valores da ETr horária estimada pelo SEBAL no instante da passagem do satélite. Observa-se que houve boas concordâncias entre os resultados em todos os dias estudados, o que é

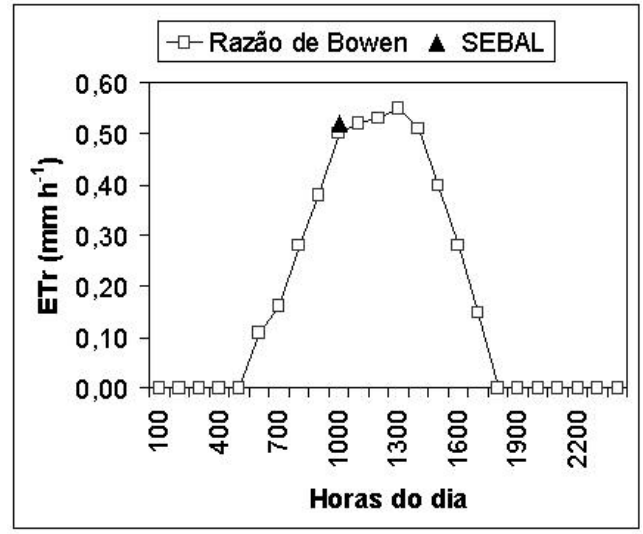

a)

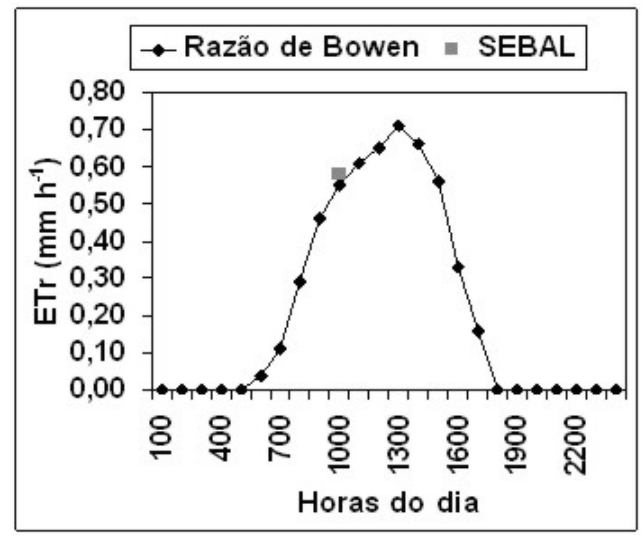

c)

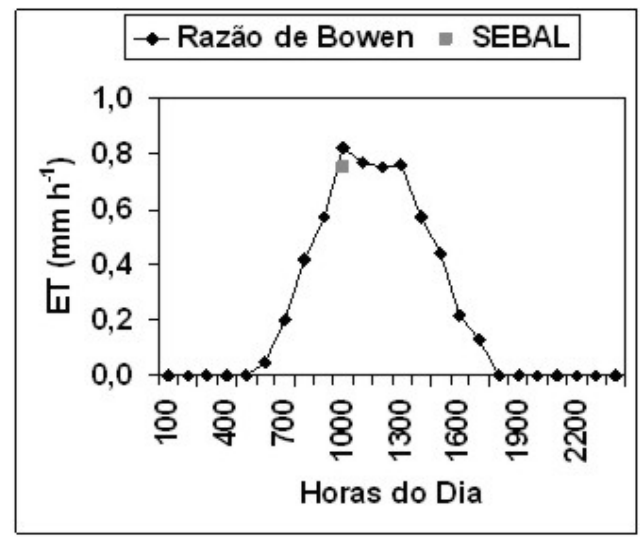

e)

Figura 8 - Ciclo diurno da ETr com médias horárias obtidas por razão de Bowen e a ETr horária estimada pelo SEBAL nos dias: a) 29/09, b) 15/10, c) $31 / 10$ e d) $16 / 11$ para a cultura do algodão e nos dias e)15/10 e f) 31/10 para a cultura da mamona. evidenciado na Tabela onde se verifica que os erros relativos entre os resultados medidos (razão de Bowen) e estimado (SEBAL) foram inferiores a $10 \%$. No entanto, vale a pena lembrar que os valores horários medidos são baseados em médias de 20 minutos e o resultado estimado pelo SEBAL é um valor integrado num intervalo de uma hora a partir do resultado instantâneo do LE para o momento do imageamento. Segundo Allen et al. (2002) esse resultado expressa a ET para o intervalo de 9:00 as 10:00 h.

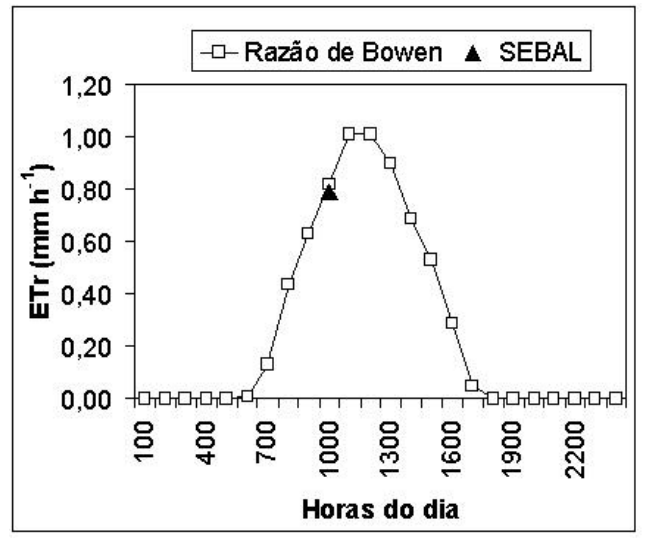

b)

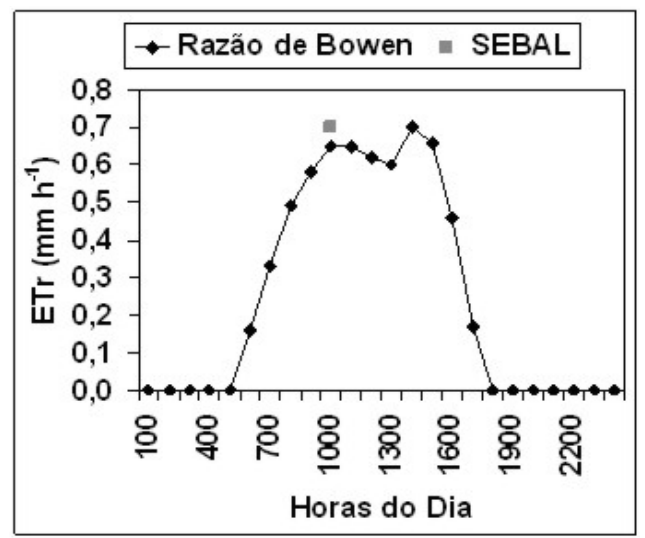

d)

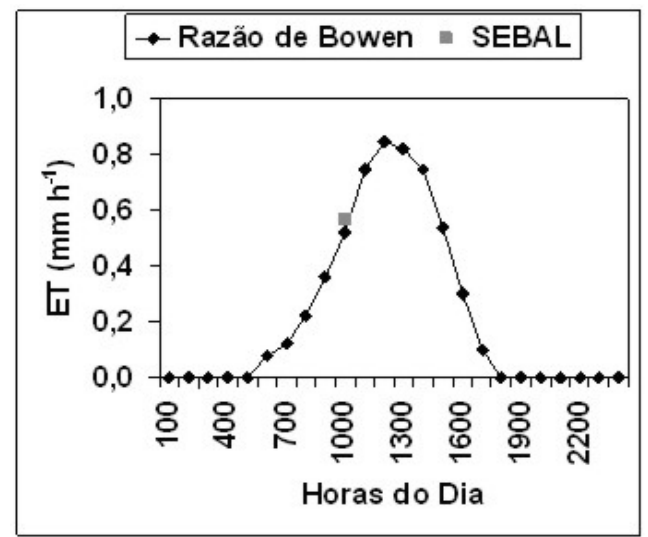

f) 
Tabela 1 - Evapotranspiração real horária das culturas do algodão e mamona obtidas pela técnica de razão de Bowen e pelo algoritmo SEBAL, e os módulos dos erros absoluto e relativo.

\begin{tabular}{cccccc}
\hline $\begin{array}{c}\text { Dias do } \\
\text { Ano } \\
\text { Estudados }\end{array}$ & Cultura & $\begin{array}{c}\text { ET } \\
(\mathbf{S E B A L )} \\
\left(\mathbf{m m ~ h} \mathbf{~}^{-1}\right)\end{array}$ & $\begin{array}{c}\text { ET (Razão de } \\
\text { Bowen) }_{\left(\mathbf{m m ~ h}^{-1}\right)}\end{array}$ & $\begin{array}{c}\text { Erro } \\
\text { Absoluto } \\
\left(\mathbf{m m ~ h}^{-1}\right)^{*}\end{array}$ & $\begin{array}{c}\text { Erro } \\
\text { Relativo } \\
(\mathbf{\%})\end{array}$ \\
\hline 272 & Algodão & 0,52 & 0,50 & 0,02 & 4,0 \\
288 & Algodão & 0,82 & 0,79 & 0,03 & 3,8 \\
288 & Mamona & 0,75 & 0,83 & 0,08 & 9,6 \\
304 & Algodão & 0,55 & 0,58 & 0,03 & 5,2 \\
304 & Mamona & 0,57 & 0,52 & 0,05 & 9,6 \\
320 & Algodão & 0,65 & 0,70 & 0,05 & 7,1 \\
\hline
\end{tabular}

Nas Figuras 9 e 10 estão apresentados os gráficos com os resultados da ETr diária da cultura do algodão e da mamona, respectivamente, medidos através do método da razão de Bowen assim como os resultados da ETr diária estimados pelo SEBAL. Observa-se que os resultados são bastante concordantes, uma vez que em todos os dias os erros absolutos entre os resultado medido e estimado foram inferiores a $0,5 \mathrm{~mm} \mathrm{dia}^{-1}$, conforme apresentado na Tabela 2. Ainda na Tabela 2 pode-se observar que o erro relativo entre os resultados diários da ETr medidos e estimados foram inferiores a $10 \%$. Erros nessa magnitude foram encontrados por Trezza (2002), quando comparou com medidas lisimétricas resultados obtidos pelo SEBAL aplicado a imagens de sete datas entre os anos de 1989 e 1991 no estado americano de Idaho. Nesse estudo os erros absolutos encontrados foram menores que $1,0 \mathrm{~mm} \mathrm{dia}^{-1}$. Já Hemakumara et al. (2003) também obtiveram resultados similares para a ET mensal e Wang et al. (2005) encontraram erros absolutos, a exemplo do presente estudo, da ordem de $0,5 \mathrm{~mm} \mathrm{dia}^{-1}$.

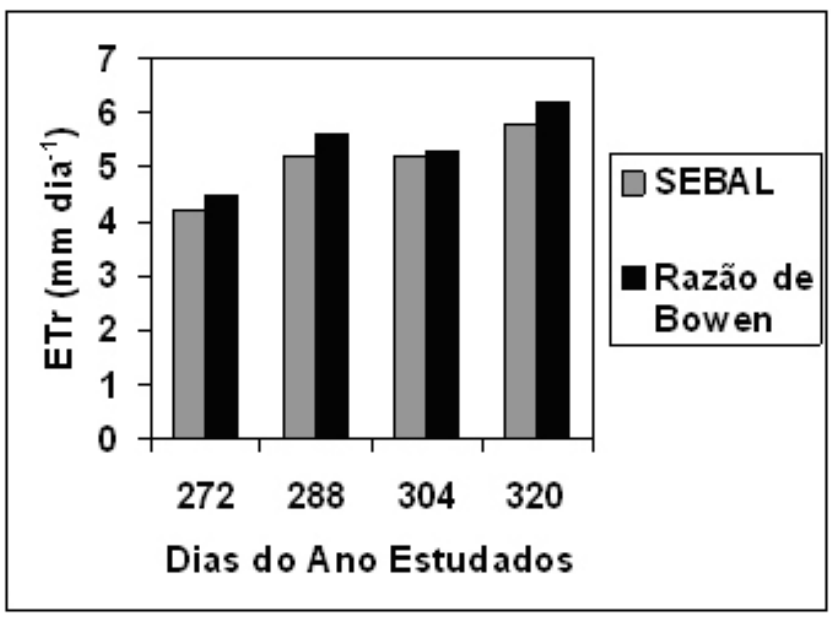

Figura 9 - Evapotranspiração diária (mm dia -1) estimada pelo SEBAL e estimada pela técnica de razão de Bowen na cultura do algodão, em Barbalha-CE.

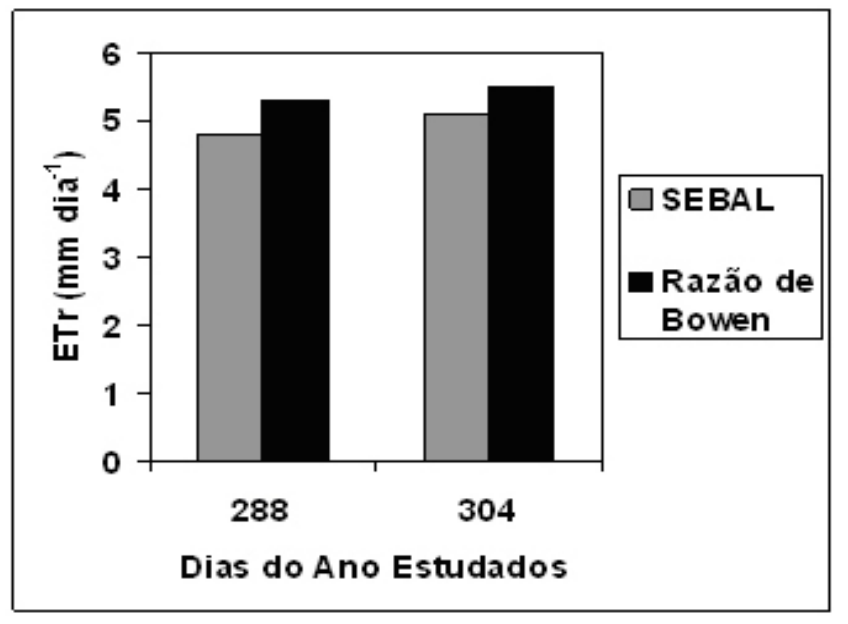

Figura 10 - Evapotranspiração diária (mm dia -1) estimada pelo SEBAL e estimada pela técnica de razão de Bowen na cultura da mamona, em Barbalha-CE

\section{CONCLUSÕES}

A ETr foi estimada pelo algoritmo SEBAL aplicado a imagens TM - Landsat 5 e seus resultados foram comparados com resultados obtidos pela técnica de razão de Bowen. As diferenças apresentadas, tanto para valores horários como para diários, foram inferiores a $10 \%$, demonstrando, dessa forma, a potencialidade da técnica.

Os resultados mostraram a capacidade do SEBAL de propiciar a variabilidade espacial da ETr, evidenciando a sua sensibilidade a diferentes ocupações do solo, o que demonstra que se aplicada a dados de alta resoluções temporal e espacial a técnica pode ser utilizado em escalas operacional e de rotina tornando-se assim, uma importante ferramenta no monitoramento de necessidades hídrica de culturas. 
Tabela 2 - Evapotranspiração real diária das culturas do algodão e mamona obtidas pela técnica de razão de Bowen e pelo algoritmo SEBAL e os módulos dos erros absoluto e relativo.

\begin{tabular}{cccccc}
\hline $\begin{array}{c}\text { Dias do } \\
\text { Ano } \\
\text { Estudados }\end{array}$ & Cultura & $\begin{array}{c}\text { ET (SEBAL) } \\
\left.\text { (mm dia }^{-1}\right)\end{array}$ & $\begin{array}{c}\text { ET (Razão } \\
\text { de Bowen) }^{\left(\mathbf{m m ~ d i a}^{-1}\right)}\end{array}$ & $\begin{array}{c}\text { Erro } \\
\text { Absoluto } \\
\text { (mm dia }^{-1} \text { ) }\end{array}$ & $\begin{array}{c}\text { Erro } \\
\text { Relativo (\%) }\end{array}$ \\
\hline 272 & Algodão & 4,2 & 4,5 & 0,3 & 6,7 \\
288 & Algodão & 5,2 & 5,6 & 0,4 & 7,1 \\
288 & Mamona & 4,8 & 5,3 & 0,5 & 9,4 \\
304 & Algodão & 5,2 & 5,3 & 0,1 & 1,9 \\
304 & Mamona & 5,1 & 5,5 & 0,4 & 7,3 \\
320 & Algodão & 5,8 & 6,2 & 0,4 & 6,5 \\
\hline
\end{tabular}

\section{REFERÊNCIAS BIBLIOGRÁFICAS}

ALLEN, R. G.; MORSE, A.; TASUMI, M.; TREZZA, R.; BASTIAANSSEN, W.; WRIGHT, J. L.; KRAMBER, W. Evapotranspiration from a satellite-based surface energy balance for Snake Plain aquifer in Idaho. Presented at the meeting of Unite States Committee on Irrigation, Drainage, and Food Control at San Luis Obispo, CA, 2002b.

ALLEN, R. G.; PEREIRA, L. S.; RAES, D.; SMITH, M. Crop evapotranspiration - Guidelines for computing crop water requirements - FAO Irrigation and drainage paper 56. Rome, Italy, 1998.

ALLEN, R.; TASUMI, M.; TREZZA, R. SEBAL (Surface Energy Balance Algorithm for Land) - Advanced Training and Users Manual - Idaho Implementation, version 1.0, $2002 a$.

ASCE-EWRI. "The ASCE Standardized reference evapotranspiration equation", ASCE-EWRI Satandardization of Reference Evapotranspiration Task Comm. Report, available at http://www.kimberly.uidaho.edu/water/ asceewri/.

ÁVILA NETO, J. Necessidades Hídricas da Videira na Região do Submédio São Francisco. UFPB/CCT/Curso de PósGraduação em Meteorologia (Dissertação de Mestrado), Campina Grande - PB, 1997.

BASTIAANSSEN, W. G. M. Regionalization of surface flux densities and moisture indicators in composite terrain: A remote sensing approach under clear skies in Mediterranean climate. PhD. Dis., CIP Data Koninklijke Biblioteheek, Den Haag, the Netherlands. 272 p., 1995.

BASTIAANSSEN, W. G. M. SEBAL - based sensible and latent heat fluxes in the irrigated Gediz Basin, Turkey. Journal of Hydrology, v.229, p. 87-100. 2000.

BASTIAANSSEN, W. G. M.; ALI, S. A new crop yield forecasting model based on satellite measurements applied across Indus Basin, Pakistan. Agriculture Ecosystems \& Environments, v.94, p.321-340, 2003.
BASTIAANSSEN, W. G. M.; PELGRUM, H.; WANG, J.; MA, Y.; MORENO, J. F. ROENRINK, G. J. VAN DER WAL, T. A remote sensing surface energy balance algorithm for land (SEBAL) 2. Validation. Journal of Hydrology, v.212-213, p.213-229,1998.

BEZERRA, M. V. C. Balanço de Energia em Áreas Irrigada Utilizando Técnicas de Sensoriamento Remoto. $108 \mathrm{f}$. Dissertação (Mestrado em Meteorologia). Departamento de Ciências Atmosféricas, Universidade Federal de Campina Grande, Campina Grande - PB, 2004.

BORGES, P. F. Crescimento, Desenvolvimento e Balanço de Radiação do Algodoeiro Herbáceo BRS - 201 em Condições Irrigadas. 87f. Dissertação (Mestrado em Meteorologia). Departamento de Ciências Atmosféricas, Universidade Federal de Campina Grande, Campina Grande - PB, 2002.

FEITOSA, J. R. P. Uso de Técnica de Sensoriamento Remoto e Imagens Landsat -TM e NOAA-AVHRR na Estimativa do Balanço de Radiação à Superfície. 164f. Tese (Doutorado em Recursos Naturais). Programa Institucional de Pósgraduação em Recursos Naturais. Universidade Federal de Campina Grande. Campina Grande, 2005.

HAFEEZ M. M.; CHEMIM Y. VAN DE GIESEN N. BOUMAN B. A. M Field Evapotranspiration in Central Luzon, Philippines, using different sensors: Landsat 7 ETM+, Terra Modis and Aster. In: Symposium on Geospatial theory, Processing and Applications, 2002, Ottawa, Canadá. ANAIS...

HEMAKUMARA, H. M.; CHANDRAPALA, L.; MOENE, A. F. Evapotranspiration fluxes over mixed vegetation areas measured from large aperture scintilometer. Agriculture Water Management, v.58, p.109-112, 2003.

MORAN, M. S.; JACKSON, R. D.; RAYMOND, L. H. GAY, L. W. SLATER, P. N. Mapping Surface Energy Balance Components by Combing Thematic Mapper and Ground - Based Meteorological Data. Remote Sensing of Environment, v.30, p.77-87, 1989.

MORSE, A., TASUMI, M., ALLEN, R. G. \& KRAMBER, W. 
J. Application of the SEBAL Methodology for Estimating Consumptive Use of Water and Streamflow Depletion in the Bear River Basin of Idaho through Remote Sensing - Final Report. Idaho Department of Water Resources - University of Idaho, 2000.

NAGLER, P. L.; SCOTT, RL; WESTENBURG, C.; CLEVERLY, J. R.; GLENN, E. P.; HUETE, A. R. Evapotranspiration on western U.S. rives estimated using the Enhanced Vegetation Index from MODIS and data from eddy correlation and Bowen ratio flux towers. Remote Sensing of Environment, v.97, p.337-351, 2005.

RODRIGUES, M. F. G. Necessidades Hídricas, Crescimento e Desenvolvimento do Algodoeiro, cultivar BRS 201. 132f. Tese (Doutorado em Recursos Naturais). Programa de PósGraduação em Recursos Naturais, Universidade Federal de Campina Grande, Campina Grande-PB, 2003.

SAMARASINGHE, G. B. Growth and yields of Sri Lanka's major crops interpreted from public domain satellites. Agriculture Water Management, v.58, p.145-157, 2003.

SILVA, B. B. da.; LOPES, G. M.; AZEVEDO, P. V. Balanço de radiação em áreas irrigadas utilizando imagens Landsat
5 - TM. Revista Brasileira de Meteorologia, v.20, n.2, p.243-252, 2005.

SILVA, Bernardo B. da ; BEZERRA, Marcus Vinícius Cândido - Determinação dos fluxos de calor sensível e latente na superfície utilizando imagens TM - Landsat 5. Revista Brasileira de Agrometeorologia, Piracicaba, SP, v.14, p.110, 2006.

TIMMERMANS, W. J.; MEIJERINK, A. M. J. Remotely sensed actual evapotranspiration: implications for groundwater in Botswana. International Journal of Applied Earth Observation, v. 1, Issue 3-4, p.222-233, 1999.

TREZZA, R. Evapotranspiration using a satellite-based surface energy balance with standardized ground control. $247 \mathrm{f}$. Thesis (Doctor of Philosophy in Biological and Agricultural Engineering). Utah State University. Logan, Utah, 2002.

WANG, J.; SAMMIS, C. A.; MEIER, L.; SIMMONS, D. R.; SAMANI, Z. A Modified Sebal Model for Spatially Estimating Pecan Consumptive Water Use for Las Cruces, New Mexico. Disponível em: http://ams.cofex.com/ams/ pdfpapers/92012.pdf. Acesso em: 07 de Julho de 2005. 